\title{
CARACTERIZAÇÃO DE BANCO DE SEMENTES DO SOLO, EM ÁREA DE MATA CILIAR NAS MARGENS DA CACHOEIRA DOMINGOS LOPES, MORRO DO CHAPÉU
}

\author{
$\underline{\text { Robson de Jesus Santos }^{1} \text {; Flavio França }}{ }^{2}$; Efigênia de Melo²; Carlos Junior R. dos \\ Santos ${ }^{3}$ \& Douglas F. Mendes ${ }^{3}$ \\ 1. Bolsista PIBIC/CNPq, Graduando em Agronomia, Universidade Estadual de Feira de Santana, e-mail: \\ robssantos17@hotmail.com \\ 2. Orientadores, Departamento de Ciências Biológicas, Universidade Estadual de Feira de Santana, e-mail: \\ \{franca.flavio@gmail.com\} efidemelo@hotmail.com \\ 3. Participantes do projeto, Departamento de Ciências Biológicas, Universidade Estadual de Feira de Santana, e-mail: \\ \{carlosrocha95santos@gmail.com\}douglamendes1705@hotmail.com
}

PALAVRAS-CHAVE: florística, germinação, preservação de mananciais

\section{INTRODUÇÃO}

A cachoeira Domingos Lopes é um manancial perene que fornece água para a Bacia do Jacuípe, sendo sua manutenção essencial para permanência do próprio rio Jacuípe e consequentemente para os mananciais existentes na região de Feira de Santana. A vegetação ciliar ao longo desta tem papel importante na manutenção do equilíbrio ecológico, protege o solo e os recursos hidrológicos, contém o assoreamento, auxilia na preservação da biodiversidade e qualidade da água (MARMONTEL \& RODRIGUES, 2015). Segundo Lacerda et al. (2010) podem dispor-se a distâncias variadas da margem além de delimitar o ecossistema terrestre do aquáticos, com variações na estrutura e composição florística.

Caracteriza-se como banco de sementes do solo todas as sementes existentes no mesmo ou serrapilheira viável, em uma determinada área e em um determinado momento. Este é um sistema, no qual se verifica a entrada e saída de sementes por meio de chuva de sementes e dispersão, sendo transitório quando as sementes germinam num período de um ano ou persistentes quando essas permanecem no solo por período superior a um ano (CALDATO et al., 1996).

Partindo da premissa de conhecimento sobre composição florística deste, tem-se um importante instrumento para entender a evolução de uma determinada espécie, sendo possível assim, projetar a recuperação da área (COSTA et al., 2013). Além, de possibilitar o estabelecimento de uma vegetação parecida com as condições naturais (SANTOS et al., 2017).

Assim, o objetivo deste trabalho foi conhecer e comparar a composição e densidade do banco de sementes do solo nas margens da cachoeira Domingo Lopes.

\section{MATERIAL E MÉTODOS}

Segundo Costa et al. (2013) os métodos mais aplicados em análise de banco de sementes são os de germinação e contagem. A Contagem engloba diferentes técnicas de extração das sementes, sendo a técnica de separação manual adotada no estudo, já a germinação baseia-se na emergência de plântulas do solo coletado da área de estudos também adotada para análise. 
Para cada lado da cachoeira Domingo Lopes, definidas a favor do fluxo d'água em margem direita e esquerda foram amostrados 10 transectos de $50 \mathrm{~m}$ em intervalo de $50 \mathrm{~m}$, sendo que, em cada transecto houve três pontos de coleta, o primeiro ponto a $0 \mathrm{~m}$ da margem, o segundo a $25 \mathrm{~m}$ e o terceiro a $50 \mathrm{~m}$. Com o uso de uma fita métrica foi medida uma área de solo: 0,40 x 0,20 e 0,05 m de profundidade (amostra) retirando-se $\left(0,004 \mathrm{~m}^{3}\right.$ de solo), que foi colocado em saco plástico, transparente, identificado e conduzido ao campus da Universidade Estadual de Feira de Santana (UEFS). No laboratório de Taxonomia Vegetal (TAXON), foi retirado 10\% de solo de cada amostra para contagem manual de sementes utilizando o método de separação manual, o restante do material foi colocado em caixas de arquivo morto e condicionado em casa de vegetação. Todas as amostras foram irrigadas durante 180 dias para germinação de possíveis sementes existente no solo. As plântulas emergentes no experimento foram contabilizadas e conduzidas até a floração ou porte físico que possibilitou sua identificação e herborizadas para fins de estudo botânicos. Foi estimado a densidade de sementes no solo (área $\mathrm{m}^{2}$ ) por ambos os métodos para as margens da cachoeira, analisados por meio da estatística descritiva. $\mathrm{O}$ teste não paramétrico de Kruskal Wallis a $95 \%$ de confiança foi utilizado para verificar diferenças significativas na densidade de sementes do solo para os diferentes pontos de coleta da área ciliar de cada margem.

\section{RESULTADOS E DISCUSSÃO}

A densidade média total de sementes estimada pelo método de separação manual foi superior para margem direita 18,33 sementes por $\mathrm{m}^{2}$ e de 17,08 semente por $\mathrm{m}^{2}$ para margem esquerda. Porém a estimativa pelo método de emergência de plântulas indicam densidade média total de sementes superior para a margem esquerda 28,33 sementes por $\mathrm{m}^{3}$ e 22,92 sementes por $\mathrm{m}^{2}$ para margem direita. Para ambos os métodos não houve diferença significativas entre os pontos nas margens pelo teste de Kruskal Wallis ( $p>0,05)$. Santos et al. (2017) analisando o banco de sementes na área ciliar do rio Jacuípe estimou densidade de sementes no solo superiores, não verificando diferença significativas para o método de emergência de plântulas corroborando com os resultados, contudo a estimativa com os dados da catação manual indicou diferença significativas entre os pontos. Para Costa et al. (2013) além de ser mais laborioso o método de catação manual de sementes possibilita superestimar o banco de sementes, uma vez que, também contabiliza sementes inviáveis.

Foram verificadas para margem direita da cachoeira a partir da emergência de plântulas, posteriormente identificadas 14 espécies vegetais (Tabela 01). Das espécies encontradas 78,57 \% são herbáceas e apenas 14,29\% são de porte arbóreo Schinus terebinthifolius Raddi (Anarcadiaceae), Pithecellobium diversifolium Benth. (Fabaceae).

$\mathrm{Na}$ margem esquerda da cachoeira foi identificada 8 espécies (Tabela 02), figurado em 8 famílias, 75\% das espécies são herbáceas e apenas 12,5\% arbórea Trema micrantha (L.) Blume (Cannabaceae). Santos et al. (2017) verificou que 70,59\% das espécies presente no banco de sementes do solo do rio Jacuípe foram herbáceas. Alvarenga et al. (2006) em avaliação do banco de sementes do solo em duas nascentes em Lavras-MG, constatou a ausências de espécies arbóreas, alertando para importância da metodologia aplicada. 
Tabela 01: Plantas identificadas na margem direita da cachoeira $(X=$ local onde emergiu a espécie)

\begin{tabular}{|c|c|c|c|c|}
\hline Familia/Espécie & $\mathbf{0 M}$ & 25M & 50M & Forma de Vida \\
\hline \multicolumn{5}{|l|}{ Anarcadiaceae } \\
\hline Schinus terebinthifolius Raddi & $\mathrm{X}$ & & & Árvore \\
\hline \multicolumn{5}{|l|}{ Asteraceae } \\
\hline Emilia sonchifolia (L.) DC. ex Wigh & $\mathrm{X}$ & $\mathrm{X}$ & $\mathrm{X}$ & Erva \\
\hline \multicolumn{5}{|l|}{ Commelinaceae } \\
\hline Commelina benghalensis L. & & & $\mathrm{X}$ & Erva \\
\hline \multicolumn{5}{|l|}{ Euphorbiaceae } \\
\hline Euphorbia hyssopifolia L. & & & $\mathrm{X}$ & Erva \\
\hline \multicolumn{5}{|l|}{ Fabaceae } \\
\hline Mimosa pudica $\mathrm{L}$. & $\mathrm{X}$ & $\mathrm{X}$ & $\mathrm{X}$ & Erva \\
\hline Pithecellobium diversifolium Benth. & & $\mathrm{X}$ & & Árvore \\
\hline \multicolumn{5}{|l|}{ Molluginaceae } \\
\hline \multicolumn{5}{|l|}{ Poaceae } \\
\hline Paspalum paniculatum $\mathrm{L}$. & $\mathrm{X}$ & & & Erva \\
\hline Chloris barbata $\mathrm{Sw}$. & $\mathrm{X}$ & & & Erva \\
\hline Dactyloctenium aegyptium (L.) Willd & $\mathrm{X}$ & $\mathrm{X}$ & $\mathrm{X}$ & Erva \\
\hline \multicolumn{5}{|l|}{ Portulacaceae } \\
\hline Portulaca oleracea $\mathrm{L}$. & & $\mathrm{X}$ & & Erva \\
\hline Portulaca hirsutissima Cambess. & & & $\mathrm{X}$ & Erva \\
\hline Portulaca mucronata Link & $\mathrm{X}$ & & & Erva \\
\hline \multicolumn{5}{|l|}{ Solanaceae } \\
\hline Solanum cf. palinacanthum Dunal & & $\mathrm{X}$ & $\mathrm{X}$ & Arbusto \\
\hline
\end{tabular}

Tabela 02: Plantas identificadas na margem esquerda da cachoeira ( $\mathrm{X}=$ local onde emergiu a espécie)

\begin{tabular}{|c|c|c|c|c|}
\hline Familia/Espécie & $\mathbf{0 M}$ & 25M & 50M & Forma de Vida \\
\hline \multicolumn{5}{|l|}{ Asteraceae } \\
\hline Emilia sonchifolia (L.) DC. ex Wigh & & $\mathrm{X}$ & $\mathrm{X}$ & Erva \\
\hline \multicolumn{5}{|l|}{ Cannabaceae } \\
\hline Trema micrantha (L.) Blume & & $\mathrm{X}$ & & Árvore \\
\hline \multicolumn{5}{|l|}{ Commelinaceae } \\
\hline Commelina benghalensis $\mathrm{L}$. & $\mathrm{X}$ & & & Erva \\
\hline \multicolumn{5}{|l|}{ Molluginaceae } \\
\hline $\begin{array}{l}\text { Mollugo verticillata } \mathrm{L} \text {. } \\
\text { Poaceae }\end{array}$ & \multicolumn{3}{|c|}{ Poaceae } & Erva \\
\hline Chloris barbata $\mathrm{Sw}$. & $\mathrm{X}$ & & & Erva \\
\hline \multicolumn{5}{|l|}{ Portulacaceae } \\
\hline Portulaca mucronata Link & $\mathrm{X}$ & $\mathrm{X}$ & & Erva \\
\hline \multicolumn{5}{|l|}{ Rubiaceae } \\
\hline Rubiaceae sp. & & & $\mathrm{X}$ & Erva \\
\hline \multicolumn{5}{|l|}{ Solanaceae } \\
\hline Solanum cf. palinacanthum Dunal & & $\mathrm{X}$ & $\mathrm{X}$ & Arbusto \\
\hline
\end{tabular}


Foi verificado no estudo para método de emergência de plântulas maior riqueza de espécies presente no banco de sementes do solo para a margem direita, sendo contabilizadas 14 espécies e apenas 8 espécies para margem esquerda. Os resultados confirmam a existência do banco de sementes no solo nas duas margens da cachoeira, com predomínio de espécies herbáceas em relação as espécies arbóreas e arbustivas, com respaldo nos estudos de Siqueira (2002).

As espécies arbóreas encontradas nas margens da cachoeira podem ser utilizadas em programas de recuperação da área ciliar, do local de estudo, respeitando sua distribuição no espaço. A verificação destas espécies pela análise de emergência de plântulas indicam que são espécies capazes de sobreviver, ou que já se estabeleceram no local. Segundo Peres et al. (2009) está é uma alternativa para restabelecimento das condições peculiares existentes antes de ações antrópicas.

\section{CONSIDERAÇÕES FINAIS}

$\mathrm{O}$ estoque de sementes no solo da cachoeira Domingos Lopes e formado majoritariamente por espécies herbáceas, quando comparado a plantas arbóreas. As espécies arbórea verificadas neste estudo podem ser utilizadas em programas de recomposição da área ciliar respeitando sua disposição no sistema. Análise do banco de sementes pelo método de emergência de plântulas, mostra-se mais eficaz e próximo da situação real da unidade estudada.

\section{REFERÊNCIAS}

ALVARENGA, A. P; PEREIRA, I. M. PEREIRA, S. A. Avaliação do banco de sementes do solo, como subsídio para recomposição de mata ciliar, no entorno de duas nascentes na região de Lavras-MG. Revista Científica Eletrônica de Agronomia, ano. V, n. 9, p.1-15, 2006.

CALDATO, S. L; FLOSS, P. A; CROCE, D. M; LONGHI, S. J. Estudo da regeneração natural, banco de sementes e chuva de sementes na reserva genética florestal de caçador, SC. Ciência Florestal, v. 6, n. 1, p.27-38, 1996.

COSTA, J. R.; FONTES J. R. A.; MORAES, R. R. Bancos de Sementes do Solo em Áreas Naturais e Cultivos Agrícolas 2013. - Manaus: Embrapa Amazônia Ocidental, 2013.

LACERDA, A. V., BARBOSA, F. M., SOARES, J. J. \& BARBOSA, M. R. V. Flora arbustiva-arbórea de três áreas no semiárido paraibano, Brasil. Biota Neotropica. 10(4): 275-284. 2010.

MARMONTEL, C. V. F; RODRIGUES, V. A. Parâmetros indicativos para qualidade da água em nascentes com diferentes coberturas de terra e conservação da vegetação ciliar. Floresta e Ambiente, v. 22, n. 2, p.1-23, 2015.

PERES, M. A; PINTO, L. V. A; LOURES, L. Avaliação dos bancos de sementes do solo de fragmentos florestais de mata estacional semidecidual clímax e secundária e seu potencial em recuperar áreas degradadas. Revista Agrogeoambiental, v. 1, n. 2, p.121-133, 2009.

SANTOS, R. J; FRANÇA, F. MELO, E, CARVALHO, M. S; VASCONCELOS, M, C. Banco de sementes do solo em floresta ciliar do rio Jacuípe (Bacia do Paraguaçu), Feira de Santana, Bahia, Brasil. Anais XXI Seminário de Iniciação Científica (2017).

SIQUEIRA, L. P. Monitoramento de áreas restauradas no interior do Estado de São Paulo, Brasil. 2002. 116p. Dissertação (Mestrado em Conservação e Ecossistemas Florestais). Escola Superior de Agricultura Luiz de Queiroz. Piracicaba, SP. 2002. 